\title{
Endoscopic removal of a gastric bezoar consisting of self-expanding spray foam used for insulating window frames
}

A 61-year-old man ate polyurethane pieces made of self-expanding spray foam. He presented to the emergency department 3 weeks later with upper abdominal pain. Routine laboratory tests were normal. Esophagogastroduodenoscopy (EGD) revealed a bezoar ( $\bullet$ Fig. 1 a) and three deep ulcers in the gastric corpus ( Fig. 1 b). The bezoar was approximately $8 \mathrm{~cm}$ in diameter, nonadherent, nonobstructive, gray, shiny and of hard consistency.

EGD was repeated twice with the patient sedated by propofol to extract the bezoar, which took a total endoscopy time of 7 hours. As all endoscopic instruments such as snares were slipping on the surface of the bezoar and lithotripsy Dormia baskets were too small, a gutter was dug around the whole circumference of the bezoar to allow it to be grasped with a polypectomy snare. To do so, a rat-tooth and alligatorjaw grasping forceps (FG-47L-1; Olympus, Tokyo, Japan) was used because it presented a large opening diameter $(14.9 \mathrm{~mm})$, which accelerated the process, and the rat-teeth did not slip over the surface of the bezoar ( $\nabla$ Fig. 1 c). A $55 \times 25-\mathrm{mm}$ internal-diameter polypectomy snare (Sonnet; Cook Medical, Limerick, Ireland) was inserted into the gutter and firmly closed to split the bezoar ( $\bullet$ Fig. 1 d). The process was repeated until the size of the fragments allowed atraumatic extraction (๑ Fig. 2).

At the end of the first EGD, particular attention was paid to not leaving fragments of a size less than $3 \mathrm{~cm}$ in the stomach, which could have migrated into the small bowel and caused ileus. No complications occurred and proton pump inhibitors were prescribed; the patient was doing well at 1-month follow-up.

Expanding spray foam is made of polyurethane or acrylic latex; when the spray lands on surfaces it expands and foams up, then hardens to an aerated material. As polyurethane is highly inflammable, we did not use electrosurgical devices to fragment the bezoar but in vitro application of argon plasma coagulation on harvested fragments had almost no effect. The ulcers were likely to have been caused by local pressure on the gastric wall, as
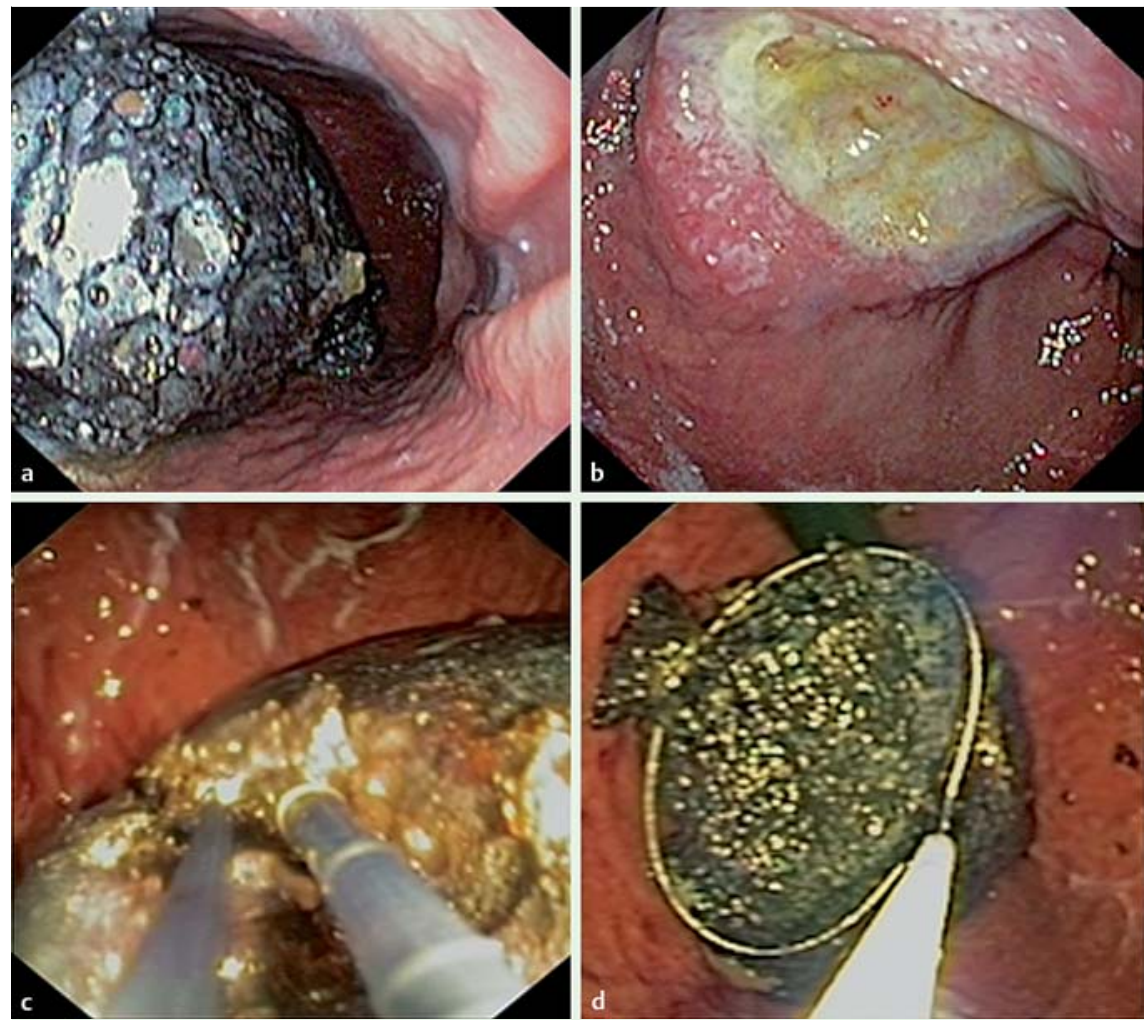

Fig. 1 Endoscopic views showing: a the polyurethane bezoar in the gastric corpus; $\mathbf{b}$ a deep gastric ulcer caused by the bezoar; $\boldsymbol{c}$ the gutter dug into the whole circumference of the bezoar to facilitate grasping it; $\mathbf{d}$ the polypectomy snare used to split the bezoar.

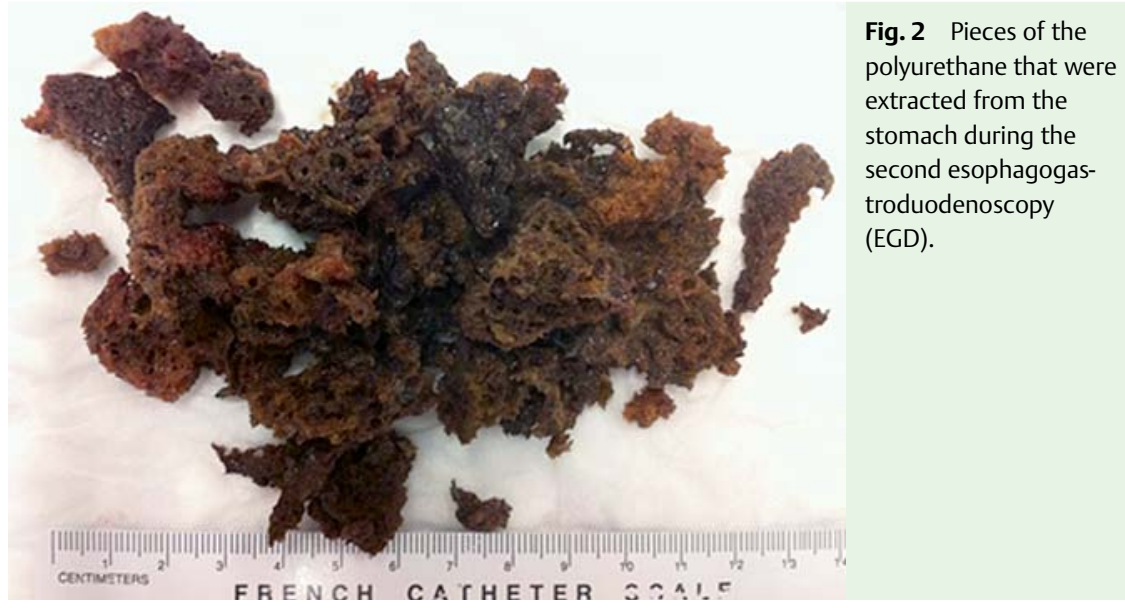

has been reported with intragastric balloons used for weight loss [1,2]. A case of polyurethane foam ingestion complicated by small bowel obstruction in a patient who underwent surgery has been reported [3]; to the best of our knowledge, this is the first case of successful endoscopic ex- traction of a gastric bezoar made of selfexpanding foam. Such bezoars are part of a new entity called plastobezoar [4].

Endoscopy_UCTN_Code_TTT_1AO_2AL

Competing interests: None 
M. Girardin, E. Giostra, J.-M. Dumonceau Division of Gastroenterology and Hepatology, Geneva University Hospitals, Geneva, Switzerland

\section{References}

1 Benjamin SB, Maher KA, Cattau EL Jr et al. Double-blind controlled trial of the GarrenEdwards gastric bubble: an adjunctive treatment for exogenous obesity. Gastroenterology 1988; 95: $581-588$

2 Dumonceau JM. Evidence-based review of the Bioenterics Intragastric Balloon for weight loss. Obes Surg 2008; 18: 1611 1617

3 Medani M, Myers E, Bryan Kenny B, Waldron $D$. Small bowel obstruction secondary to migration of a fragment of lithobezoar: a case report. Cases J 2009; 2: 9155 - 9157

4 Misra SP, Dwivedi M, Misra V. Endoscopic management of a new entity - plastobezoar: a case report and review of literature. World J Gastroenterol 2006; 12: $6730-6733$
Bibliography

DOI $10.1055 / \mathrm{s}-0030-1256702$

Endoscopy 2011; 43: E372 -E373

(c) Georg Thieme Verlag KG Stuttgart · New York . ISSN 0013-726X

\section{Corresponding author} M. Girardin, MD

Division of Gastroenterology and Hepatology Geneva University Hospitals Rue Gabrielle-Perret-Gentil 4 $\mathrm{CH}-1211$ Geneva 14 Switzerland

Fax: +41-22-3729366

marc.girardin@hcuge.ch 